This item was submitted to Loughborough's Research Repository by the author.

Items in Figshare are protected by copyright, with all rights reserved, unless otherwise indicated.

\title{
Microphase separation, stress relaxation and creep behavior of polyurethane nanocomposites
}

PLEASE CITE THE PUBLISHED VERSION

PUBLISHER

(C) John Wiley \& Sons

LICENCE

CC BY-NC-ND 4.0

\section{REPOSITORY RECORD}

Xia, Hesheng, Mo Song, Zhongyi Zhang, and Mel Richardson. 2007. "Microphase Separation, Stress

Relaxation and Creep Behavior of Polyurethane Nanocomposites". figshare. https://hdl.handle.net/2134/2724. 
This item was submitted to Loughborough's Institutional Repository by the author and is made available under the following Creative Commons Licence conditions.



For the full text of this licence, please go to: http://creativecommons.org/licenses/bync-nd/2.5/ 


\title{
Microphase Separation, Stress Relaxation and Creep Behavior of Polyurethane Nanocomposites
}

\author{
Hesheng Xia ${ }^{\mathrm{a}}$, Mo Song ${ }^{\mathrm{a}^{*}}$, Zhongyi Zhang ${ }^{\mathrm{b}}$, Mel Richardson ${ }^{\mathrm{b}}$
}

Published in: Journal of Applied Polymer Science, 103(5), pp. 2992-3002

Address: a: Institute of Polymer Technology and Materials Engineering

Loughborough University

Loughborough, Leicestershire, LE11 3TU

UK

b: Department of Mechanical and Design Engineering

University of Portsmouth

Anglesea Building, Portsmouth, Hampshire, PO1 3DJ

UK

Corresponding author: Mo Song

Fax: $\quad(+44) 1509223949$

Tel: $\quad(+44) 1509223160$

Keywords: Exfoliation, Clay, Polyurethane Nanocomposite

* To whom correspondence should be addressed 


\section{Abstract:}

The microphase separation of polyurethane (PU) nanocomposite was studied. The result suggests that the addition of clay leads to a decrease in the size of hard domain and an increase in the degree of microphase separation. The stress relaxation and creep behavior of blank PU and PU/clay nanocomposites were investigated. The relaxation time spectrum and retardant time spectrum were derived according to the generalized Maxwell model and Voigt model with a Tikhonov regularization method. The characteristic relaxation time was identified with the corresponding relaxation process. At a small strain, the relaxation was mainly attributed to uncoiling/disentangling of soft segment chain network in the soft phase, with a single characteristic relaxation time in the range of 5 100s. The increase in the hard segment content leads to a decrease in the relaxation time, and the addition of clay leads to an increase in the relaxation time. At large strains, the multi-peak relaxations occurred, and they were attributed to the breakup of interconnected hard domains and pull-out of soft segment chains from hard domains, together with the disentangling of soft segment chain network in the soft phase. The creep results are in consistent with that of the stress relaxation. The relaxation and creep behavior were related to microphase separation of polyurethane. This study suggested that the relaxation spectrum $\mathrm{H}(\tau)$ can be used to examine the complicated relaxation processes for a multi-phase and multi-component polymer system.

Keywords: Microphase separation, polyurethane, nanocomposite, stress relaxation, creep 


\section{Introduction}

Polyurethane (PU)/clay nanocomposite has attracted increasing interest recently [1-11]. The introduction of clay can improve tensile strength and elongation of PU. The properties of PU/clay nanocomposites are dependent on the molecular structure of PU, mainly on microdomain structure, dispersion state of clay, i.e. intercalation or exfoliation, and interaction between clay and PU. One of the most important features of polyurethane is microphase separation due to its thermodynamic incompatibility between the soft and hard segments [12]. Microphase separation leads to the formation of two-phase structure, i.e. hard domains rich in hard segments and a soft phase rich in soft segments. The degree of microphase separation influences the mechanical and viscoelastic properties of polyurethane. In order to disclose the fundamental mechanism about the improvement in PU/nanocomposite properties, the effect of clay on microphase separation of polyurethane has been investigated by several researchers, it appears that there is no consensus. Tien et al reported that the degree of microphase separation in the hard segments of the synthesized montmorillonite(MMT)/polyurethane nanocomposites decreased with the increasing amount of MMT, but reached plateau values at $5 \mathrm{wt} \%$ MMT concentration. [4]. Dai et al found that the degree of microphase separation (i.e. hydrogen bonding index) first increased with the clay ratios in the PU matrix and then decreased [11] .

$\mathrm{PU} /$ clay nanocomposites are viscoelastic, as a consequence, the long-term strength is one of their major concerns. Stress relaxation and creep was widely used to investigate the timedependent viscoelastic properties of polymer. Relaxation is a process of reorganization of the structure to reach the thermodynamic equilibrium after a perturbation. It involves the structure change at different length scales, and the required time called relaxation time is on a wide range of time scales. In general, the combination of mechanical elements, usually springs and dashpots, can be used to model the viscoelastic response of polymer materials. It 
is well known that Maxwell and Voigt model were widely used to depict the stress relaxation and creep behavior, respectively [13]. The relaxation time spectrum and retardant time spectrum related to specific molecular architectures can be derived from the two models. The spectrum's sensitivity to small changes in molecular connectivity makes it a powerful tool to distinguish small differences in otherwise undistinguished materials [14]. For a heterogeneous material, the spectrum is strongly related to the microdomain structure. Relaxation or retardant time spectrum can qualitatively disclose the relationship between the microstructure and characteristic relaxation time. Also, the broadness of the spectrum can reflect the polydispersity of the relaxation elements. For polyurethane with two phase structure, relaxation or retardant time spectrum can distinguish some information of hard domain and soft phase structures of polyurethane based on the characteristic relaxation peak.

It is interesting to know how the addition of clay affects the microphase separation of PU and further the stress relaxation and creep behavior of polyurethane/clay nanocomposites. In this study, we tried to identify the relaxation peak in the relaxation spectrum and disclose some relationships between microphase separation and stress relaxation and creep behavior in PU/clay nanocomposites.

\section{Experimental}

Materials. Poly(propylene glycol) (Lupranol 2090, molecular weight=6000, function=3), was kindly provided by Elastogran U.K. Ltd. 4,4'-Methylene bis(cyclohexyl isocyanate) (MDI) was kindly provided by Hyperlast Ltd., UK. 1.4-butanediol was purchased from Aldrich Chemical Company. Dabco-33LV as the catalyst was obtained from Air Products and Chemicals. The organoclay C20A were purchased from Southern Clay Products, Inc., USA. The modifiers for organoclay $\mathrm{C} 20 \mathrm{~A}$ is dihydrogenated tallow quaternary ammonium (2M2HT). 
Preparation of PU-organoclay nanocomposites. Polyurethane at different hard segment content, i.e. $16 \%, 26 \%, 36 \%$ and $46 \%$ was prepared through one-shot process. Polyurethane /organoclay nanocomposites at a hard segment content of $26 \%$ were prepared. The $-\mathrm{NCO} / \mathrm{OH}$ ratio was kept at 1.1:1 for every sample. Typically, $19.4 \mathrm{~g}$ of polyol and $0.6 \mathrm{~g}$ of clay were blended and stirred for $4 \mathrm{~h}$ at 80 . The polyol/clay mixture was blended with $0.85 \mathrm{~g}$ of 1,4butanediol, $5.96 \mathrm{~g}$ of MDI and $0.03 \mathrm{~g}$ of Dabco-33LV as a catalyst at room temperature for 1 min and was vacuum-degassed for $3 \sim 5 \mathrm{~min}$ to remove the bubbles. Then the viscous prepolymer was poured into an O-ring metal mold and cured at 50 for $24 \mathrm{~h}$ and 80 for $72 \mathrm{~h}$ to obtain PU-organoclay nanocomposites.

\section{Characterization}

Fourier transform infrared (FTIR) spectra of polyurethane/clay nanocomposite films were recorded on a Mattson 3000 FTIR spectrometer by using a ATR mode. The spectra were collected from 4000 to $400 \mathrm{~cm}^{-1}$, with a $4 \mathrm{~cm}^{-1}$ resolution over 120 scans.

Small-angle X-ray scattering (SAXS) experiment were illustrated in reference [10]. It was carried out on the Kratky Compact Small Angle System with a stationary-anode copper-target X-ray tube (wavelength $1.542 \AA$ ) at room temperature. The fine-focus X-ray generator was operated at $45 \mathrm{kV}$ and $40 \mathrm{~mA}$.

The morphology of the samples was examined on sectioned specimens by Atomic Force Microscopy (AFM) using a TA Instruments 2990 Micro-Thermal Analyzer incorporating a ThermoMicroscopes Explorer AFM (TA Instruments, 109 Lukens Drive, New Castle, DE 19720). The operating method employed was tapping mode, simultaneously producing topographic and phase images. The PU samples were conducted an initial $50 \mu \mathrm{m} \times 50 \mu \mathrm{m}$ scan to identify areas smooth enough for analysis. Once this was achieved, a high-resolution $10 \mu \mathrm{m} \times 10 \mu \mathrm{m}$ scan was carried out.

\section{Stress relaxation}




\section{(1) Experiment}

Stress relaxation tests were carried out using a Hounsfield test machine at room temperature. For strain experiment, the same specimen was used. The specimen was deformed, then relaxed and then deformed again at a higher strain, following this sequence: $10 \%, 25 \%, 50 \%, 100 \%, 200 \%$. During the test, the specimens were stretched to a certain strain at a crosshead rate of $50 \mathrm{~mm} / \mathrm{min}$, and then held for $40 \mathrm{~min}$. For stress relaxation on different hard segment and clay content, different specimens were used for every test, and the strain was fixed at $100 \%$. The stress decay with the time was recorded. The relaxation ratio was defined as $\left(\sigma_{0}-\sigma_{\mathrm{e}}\right) / \sigma_{0}, \sigma_{0}$ is the initial stress at $\mathrm{t}=0$ at $100 \%$ strain, $\sigma_{\mathrm{e}}$ is the approximately equilibrium stress at $\mathrm{t}=40 \mathrm{~min}$.

\section{(2) Stress relaxation data analysis}

a: relaxation time spectrum

In general, discrete relaxation time spectrum can be calculated from the experimental relaxation curves using the generalized Maxwell model consisting of a set of Maxwell units connected in parallel. When the number of Maxwell elements approaches infinity, the relaxation modulus can be expressed as Laplace Transform of a continuous relaxation time spectrum $H(\tau)[13]$.

$$
E(t)=E_{e}+\int_{-\infty}^{\infty} H(\tau) e^{-t / \tau} d \ln \tau
$$

Where $\mathrm{E}(\mathrm{t})$ is the decaying modulus at the time $\mathrm{t}, \tau$ is the relaxation time, $\mathrm{E}_{\mathrm{e}}$ represents the fitted equilibrium or residual modulus at the fully decayed state. $H(\tau)$ is the relaxation time spectrum. The spectrum $H(\tau)$ cannot be measured directly. It can be obtained through inverse Laplace transform by a numerical method. The numerical inverse Laplace transform on an experimental curve was generally an ill-posed problem. In this paper the relaxation time spectra for all the samples were obtained from the curves of relaxation modulus with time by nolinear Tikhonov regularization method [15]. A total of 178 data points were selected for 
the analysis.

b: stress relaxation rate

The stress relaxation rate at $\mathrm{t}=\mathrm{t}_{0}$ can be estimated by the following equation:

$$
\left.\frac{d E(t)}{d t}\right|_{t=t_{0}}=\left.\frac{d \int_{0}^{\infty} \frac{H(\tau)}{\tau} \exp (-t / \tau) d \tau}{d t}\right|_{t=t_{0}}=\int_{0}^{\infty} \frac{H(\tau) \exp \left(-t_{0} / \tau\right)}{\tau^{2}} d \tau
$$

In order to avoid the initial experimental instability, we calculated the stress relaxation rate at $\mathrm{t}=60 \mathrm{~s}$. In a previous study, Cotton and Boonstra evaluated the relaxation rate by fitting the test data to a empirical formula, i.e. $\mathrm{f}_{\mathrm{t}}=\mathrm{f}_{1.0} \mathrm{t}^{-\mathrm{n}}$, where, $\mathrm{f}_{1.0}$ is the stress after 1 min of relaxation, $\mathrm{n}$ is the relaxation rate index of material and $\mathrm{t}$ is time in min. [16]

\section{Creep}

\section{(1) Experiment}

Creep test was performed at 30 on a TA Instruments Thermal Analysis DMA Q800. A small preload of $0.2 \mathrm{~N}$ was applied to make sure that the sample was taut. The samples were displaced at a stress of $0.2 \mathrm{MPa}$ for $120 \mathrm{~min}$ and then were recovered for $60 \mathrm{~min}$. The strain and creep compliance $J(t)$ was recorded. The creep ratio was defined as $\left(\mathrm{J}_{\mathrm{e}}-\mathrm{J}_{0}\right) / \mathrm{J}_{0}, \mathrm{~J}_{0}$ is the initial creep compliance, $\mathrm{J}_{\mathrm{e}}$ is the equilibrium creep compliance.

\section{(2) Creep data analysis}

a: retardant time spectrum

The retardant time spectra were derived according to the generalized Voigt model based on the creep compliance-time curves [13].

$$
J(t)=J_{g}+\int_{-\infty}^{\infty} L(\lambda)\left(1-e^{-t / \lambda}\right) d \ln \lambda+t / \eta_{0}
$$

Where $\mathrm{J}(\mathrm{t})$ is the creep compliance at the time $\mathrm{t}, \lambda$ is the retardant time, $\mathrm{J}_{\mathrm{g}}$ represents the fitted equilibrium creep compliance. $L(\lambda)$ is the retardant time spectrum. b: creep rate

The creep rate at $\mathrm{t}=\mathrm{t}_{0}$ can be estimated by the following equation: 


$$
\left.\frac{d J(t)}{d t}\right|_{t=t_{0}}=\left.\frac{d \int_{0}^{\infty} \frac{L(\lambda)}{\lambda}(1-\exp (-t / \lambda)) d \lambda}{d t}\right|_{t=t_{0}}=\int_{0}^{\infty} \frac{L(\lambda) \exp \left(-t_{0} / \lambda\right)}{\lambda^{2}} d \lambda
$$

In order to avoid the initial experimental instability, the creep rates at $t_{0}=60 \mathrm{~s}$ were calculated for a relative comparison.

\section{Results and discussion}

In a multi-phase system, microphase separation, i.e. microdomain composition and morphology, has a great influence on the relaxation and creep processes. In this study we first investigate the microphase separation with FTIR, SAXS and AFM, and then the stress relaxation and creep behavior. We will analyze the stress relaxation and creep behavior combined with the microphase separation of polyurethane.

\section{Microphase separation of polyurethane/clay nanocomposites}

\section{FTIR}

Phase separation is an important factor for PU physical properties. The degree of phase separation in segmented PU can be estimated according to the method of Cooper et al. [4, 17]. The hydrogen bonding was formed by the -NH groups being as proton donor and the oxygen in carbonyls of the hard segment and in ethers of the soft segment as proton acceptors. The formation of hydrogen bonding by $-\mathrm{C}=\mathrm{O}$ group can be determined by examining the peak position at $\sim 1705 \mathrm{~cm}^{-1}$ for hydrogen bonded $-\mathrm{C}=\mathrm{O}$ and at $\sim 1728 \mathrm{~cm}^{-1}$ for free $-\mathrm{C}=\mathrm{O}$. By measuring the peak intensity ratio of these two carbonyl groups, it is possible to give an estimate of the degree of hydrogen bonding. The hydrogen bonding index, $R$, can be defined as the ratio of absorption peak $A_{\sim 1703} / A_{\sim 1727}$. In association with the change of absorption peaks of NH groups, the degree of phase separation of segmented PU can be calculated. In addition, the hydrogen bonding index, $R$, can be obtained from a base-line approach method: $R=C_{\text {bonded }} \varepsilon_{\text {bonded }} / C_{\text {free }} \varepsilon_{\text {free }}=A_{\sim 1703} / A_{\sim 1727}$, where $C$ is the concentration and $\varepsilon$ is the respective extinction coefficient of bonded and free carbonyl groups. The degree of 
phase separation (DPS) can be obtained by the equation: DPS $=C_{\text {bonded }} /\left(C_{\text {bonded }}+C_{\text {free }}\right)$ or $\mathrm{DPS}=\mathrm{R} /(\mathrm{R}+1)$ [4]. Here the ratio of $\varepsilon_{\text {bonded }} / \varepsilon_{\text {free }}$ is taken as $\sim 1$ according to Cooper [17]. Figures 1 show FTIR spectra of PU/clay composites. The peak was fitted by Microcal Origin software and a curve fitting result for PU-26 were shown inside the Figure 1. The area of peak at $\sim 1728 \mathrm{~cm}^{-1}$ and $\sim 1705 \mathrm{~cm}^{-1}$ was calculated to evaluate the hydrogen bonding index, $\mathrm{R}$, and the degree of phase separation (DPS). The DPS results are shown in Figure 2. It is clear that with increasing the clay content, the degree of phase separation increased.

\section{AFM}

AFM has been proved to be an important tool to characterize the microphase-separated structure [18-21]. This technique allows simultaneous detection of phase image and height, which provides insight on the variations in topography and local stiffness. Using a tapping mode, AFM can not only image topographic features it also can map the spatial variation in surface by phase imaging. Phase imaging is quite effective for mapping the sub-micron properties of multi-component polymer systems based on the relative elasticity of individual components. Conventionally, the scales of AFM phase images are set so that the harder phase induces a higher phase offset and appears lighter where as the softer phase appears darker. Therefore, in the AFM images presented in this paper, the lighter regions correspond to the hard phase and clay particles where as the darker regions are representative of soft phase. In this study the intercalated clay is a minor composition compared to the hard domain of PU. Figure 3 shows the tapping mode phase images of PU and PU nanocomposite with $3 \%$ clay content at a hard segment of $26 \%$. The aggregates of hard domains in the magnitude of submicron with the spherical structures were observed in the blank PU. When the clay was incorporated, the size of the aggregates of hard domain was reduced. It is difficult to distinguish the clay particles and hard domain of polyurethane by AFM. The intercalated clay structures were easily observed by TEM, which was shown in our previous study [22]. In 
addition, compared to blank PU, PU nanocomposite has a clear interface and a dense hard domain structure, indicating a more complete microphase separation.

So, from FTIR and AFM, it can be concluded that with the addition of clay, the size of hard microdomain decreases and a more complete phase separation occurs. In a previous study [10], we conducted the SAXS experiment to examine the microphase morphology of PU. The degree of microphase separation also can be evaluated from SAXS experimental. The higher electron density variance is due to a higher extent of microphase separation which leads to a greater contrast in electron densities. The scattering peak height is roughly proportional to the contrast between the phases [23-24]. The scattering peak height increases with increasing the clay content, indicating a higher degree of microphase separation. The SAXS results are in consisitent with the results reported here. The reason for the change in microphase separation induced by clay particles is not very clear. Possibly, the clay particles can have the nucleation effect to induce the formation of hard domain during the reaction process.

\section{Stress relaxation of blank polyurethane}

Stress relaxation measurements can give an insight in the viscoelastic behavior of polymer. Typical stress relaxation data can be fitted to a power-law equation $E(t) \sim \mathrm{E}_{\infty}\left(1+(\mathrm{t} / \tau)^{-}\right.$

$m)$ [25] or a single stretched exponential function, $E(t)=\left(E_{0}-E_{f}\right) \exp (-t / \tau)^{\beta}+E_{f}$, a modification of the Kohlrausch-Williams-Watt (KWW) equation [26]. A single characteristic relaxation time $\tau$ can be derived. For an elastomer, the stress relaxation with the power-law decay was related to the relaxation of loops and free dangling chains attached to the hard domain [27]. Recently Hotta et al proposed a chain pullout mechanism to interpret the stretched exponential decay $[28,29]$ Gurtovenko et al thought that the stress relaxation behavior in an inhomogeneously crosslinked network may be caused by a broad size distribution of non-interacting network regions each composed of a certain number of relaxation elements (crosslinks, polydisperse 
chains, etc) [30]. Hotta extended this model to homogeneously crosslinked thermoplastic elastomers assumed thermal fluctuations induce fluctuations in size of domains of crosslinks via a chain-pullout mechanism [29]. Ortiz et al studied a single-step stress relaxation of a polydomain liquid crystalline elastomer (LCE), they found that a LCE with a domain structure has a high relaxation strength and a much faster relaxation time compared to amorphous, isotropic polyisoprene and they suggested that the origin of this relaxation takes place on a localized size scale of less than a single domain $(\sim \mu \mathrm{m})$ [31]. For a multi-phase and multi-component system, the stress relaxation is a superposition of different relaxation processes. The different relaxation processes with different relaxation elements should be related to different characteristic relaxation times $\tau$. The power-law and stretched exponential equations with a single relaxation time can not give such information. Alternatively, the quantitative description of stress relaxation as shown in equation (1) can be made according to a generalized Maxwell model based on the stress relaxation modulus data $G(t)=\sigma(t) / \varepsilon$. And the relaxation time spectrum $\mathrm{H}(\tau)$ can be derived using Lapalace transform. The $\mathrm{H}(\tau)$ value is related to relaxation rate as shown in equation (2). The multiple characteristic relaxation time and relaxation peak broadness given by relaxation time spectrum $H(\tau)$ can disclose the molecular and microdomain structure information qualitatively. The stress relaxation for polymer is attributed to chain motion and orientation, uncoiling/disentangling of polymer chain network strand, deformation and rupture of microdomain and crosslinks. Our belief is that every peak in the relaxation time spectrum should be related to a specific intrinsic structure change. In this study, in order to identify every relaxation peak in relaxation time spectrum, we first examine the hard segment content and strain effect of blank polyurethane.

\section{(1) Hard segment content}

Figure 4 and Figure 5 show the stress relaxation curves and relaxation time spectra of polyurethane with different hard segment contents. The initial stress, equilibrium stress, 
relaxation ratio, relaxation rate, and characteristic relaxation time are listed in Table 1 . With increasing the hard segment content, the initial stress and equilibrium stress, relaxation ratio and rate increased. Figure 6 shows the variation of characteristic relaxation time $\tau$ with the hard segment content. Based on the relaxation time spectrum, three points can be noted. (1) As shown in Figure 6, the characteristic relaxation time decreased with increasing hard segment content, and this decrease can be fitted to a empirical exponential equation very well: $\tau=5+957 \exp (-\mathrm{c} / 0.07)$, where $\mathrm{c}$ is the hard domain content. Based on this equation, when hard domain content was extrapolated to zero, the polyurethane without hard domain has a relaxation time of $\sim 962 \mathrm{~s}$. It is in the same magnitude of isotropic polyisoprene investigated by Ortiz et al [31]. When hard domain content was extrapolated to $100 \%$, the pure hard domain have a relaxation time of $\sim 5 \mathrm{~s}$. (2) At a $16 \%$ hard segment content, there is only one relaxation peak. And with increasing the hard segment content, another peak with a longer relaxation time appeared and became much clearer at $36 \%$ and $46 \%$ hard segment content. (3) With increasing hard segment content, the peak becomes broader. These results suggest that hard segment content has a significant effect on the relaxation of polyurethane. We will give a detailed discussion below.

\section{(2) Strain effect}

The strain plays an important role in structure change for elastomer during stress relaxation. The strain experiment was conducted at different strains $10 \%, 25 \%, 50 \%, 100 \%$ and $200 \%$ for blank PU at a $26 \%$ hard segment content. Figure 7 shows the relaxation time spectra at different strains. With the increase of strain, the characteristic relaxation time first decreased and then increased and it appears that the relaxation peak first become narrower and then broader. At a strain of $200 \%$, three characteristic peaks appeared. The multi-peak distribution at this large strain indicates a multi-relaxation process.

From the above relaxation experiments by varying the hard segment and strain, we 
attempt to identify the peak related to the relaxation process. For polyurethane elastomer, there should be three main relaxation processes: uncoiling/disentangling of soft segment chain network in the soft phase, breakup of interconnected hard domain, and pull-out of soft segment chains from hard domains. The first relaxation can take place at any strain, and the latter two relaxations only at large strains. One of our main concerns is what mechanism is responsible for the relaxation process with the characteristic peak at 5 100 s. We think this peak should be attributed to uncoiling/disentangling of soft segment chain network in the soft phase. There are two reasons for this identification: (1) as suggested above, from the strain experiment this peak always existed at a small strain (linear viscoelastic region) and large strains (nonlinear viscoelastic region). The strain experiment was conducted on one elastomer specimen following this sequence: $10 \%, 25 \%, 50 \%, 100 \%, 200 \%$. Even after several relaxation experiment, the characteristic relaxation peak at 5 100 s still existed with some shifts, suggested that the related relaxation process may be reversible. (2) From relaxation experiment with different hard segment content, the peak shifts to a larger relaxation time with the increase of soft segment content. If we attribute this peak to the structure change of hard domain, there should be another peak for soft segment chain for PU-16, however, it is clear that there is only one single peak. The peak shift with increasing soft segment content should be related to soft phase composition, i.e. the hard segment content in the soft phase. With increasing hard segment content, the hard segment in the soft phase increased, soft chain flexibility decrease (glass transition temperature increase) and elasticity decrease, thus leads to a fast stress relaxation time. For polyurethane relaxation at a large strain of $200 \%$, the observed three peaks in the relaxation spectrum (Figure 7) was attributed to three different processes. The first peak I at $\sim 6 \mathrm{~s}$ may be attributed to the breakup of interconnected hard domains, the second peak II at $\sim 47 \mathrm{~s}$ should be attributed to the disentanglement of the molecular chains in the soft domain, and the third peak III at $\sim 1443 \mathrm{~s}$ may be attributed to 
the pull-out of soft segment chains from hard domains, which takes place after the breakup of interconnected hard domain. We believed that the multi-peak appeared at a large strain of $200 \%$ was related to the breakup of interconnected hard domains. The breakup of interconnected hard domains during stretching was also detected by FTIR based on a decrease in hydrogen-bonding [32,33]. Ishihara et al reported strain-induced changes in the extent of hydrogen bonding on one elastomer [34]. They suggested that no change in the extent of hydrogen bonding of polyurethaneureas was observed up to $50 \%$ strain, and an abrupt decrease in the hydrogen bonding occurred at 100\% strain, which was followed by only a slight decrease in H-bonding at still higher elongation. Desper [35] reported an a significant decrease in a long repeat period at the strain between $100 \%$ and $200 \%$ by SAXS experiment and deduced the breakup of the hard-segment phase into smaller chunks. This present study suggested that the relaxation spectrum $\mathrm{H}(\tau)$ can characterize the rupture of interconnected hard domains of polyurethane and give more information on this dynamic process than FTIR and SAXS. In addition, we noted that with increasing the hard segment content, the relaxation spectra changed from single-peak distribution to multi-peak distribution. These results suggested that increasing hard segment content led to a more complicated relaxation process. Especially, the shape of relaxation spectrum of polyurethane with a $46 \%$ hard segment content at $100 \%$ strain is similar to that of polyurethane with a $26 \%$ hard segment content at a $200 \%$ strain. In such cases, the breakup of interconnected hard domains of polyurethane occurred and led to the multi-peak relaxation. The strain needed to break up the interconnected hard domains of polyurethane at high hard segment contents is

lower than that at low hard segment contents. This is because the interconnected hard domains of polyurethane at high hard segment contents has a larger size and could be more easily to deform and break under strain.

\section{Stress relaxation of polyurethane nanocomposite}


We have identified the relaxation peak based on the relaxation experiment of polyurethane at different hard segment contents and different strains. We will discuss the effect of clay on the relaxation time of polyurethane nanocomposites, mainly the characteristic relaxation time at 5-100s related to uncoiling/disentangling of soft segment chain network in the soft phase.

\section{(1) Effect of clay content on stress relaxation}

Figure 8 and Figure 9 show the stress relaxation curves and relaxation time spectra for polyurethane with different clay contents, respectively. The initial stress, equilibrium stress, relaxation ratio, relaxation rate, relaxation time are listed in Table 2. With the increase of clay content, the initial stress increased and the equilibrium stress nearly doesn't change except for $5 \% \mathrm{C} 20 \mathrm{~A}$. The addition of clay can improve the modulus of polyurethane elastomer, which is in consistent with our former conclusion [7, 22]. The results indicate the addition of clay has a very weak effect on the crosslink density of PU. The relaxation ratio and rate increase with the addition of clay. It is interesting to note that the characteristic relaxation time related to uncoiling/disentangling of soft segment chain network in the soft phase increased with the addition of clay. This suggested that characteristic relaxation time derived from relaxation spectrum is not always related to the overall relaxation rate, as suggested in equation 2 . The characteristic relaxation time only correlates a specific relaxation process. This is different from relaxation time obtained from the power-law equation or a single stretched exponential function, which can be taken as an evaluation of overall relaxation rate. The peak shift with clay content could be related to soft phase composition. As suggested above, the addition of clay enhanced the degree of microphase separation, that means the hard segment content in the soft phase decreased, soft chain flexibility increased and elasticity increased, thus led to a slow stress relaxation process. We noted that the trend in the change of microphase separation with clay contents is in consistent with the trend in the relaxation time. On the 
other hand, with the addition of clay, relaxation peak become broader. The broadening of relaxation spectra is associated with the increase in the diversity of soft segment chain structure due to the addition of the filler.

\section{(2) Strain effect}

The strain experiments were conducted at different strain $10 \%, 25 \%, 50 \%, 100 \%$ and $200 \%$ for $3 \% \mathrm{C} 20 \mathrm{~A} / \mathrm{PU}$ nanocomposite. Figure 10 shows the relaxation time spectra at different strains. During the test specimen was deformed, then relaxed and then deformed again at a higher strain, following this sequence: $10 \%, 25 \%, 50 \%, 100 \%, 200 \%$. The specimens were stretched to a certain strain at a crosshead rate of $50 \mathrm{~mm} / \mathrm{min}$, and then held for $40 \mathrm{~min}$. The characteristic relaxation times of PU nanocomposite at different strains are higher than that of blank polyurethane at the corresponding strain shown in Figure 8. A multi-peak distribution appeared at $100 \%$ strain for $\mathrm{PU} / 3 \% \mathrm{C} 20 \mathrm{~A}$ nanocomposites, earlier than blank polyurethane, possibly due to a faster overall relaxation rate. At a $200 \%$ strain, the relaxation spectra return to a single peak distribution. This indicated the two new relaxation processes appeared at a $100 \%$ strain involved an irreversible disruption process. This further supported that it is reasonable to attribute the two processes to the breakup of interconnected hard domains and the pull-out of soft chains from hard domains, respectively.

\section{Creep of polyurethane nanocomposites}

Creep is defined as the time-dependent permanent deformation in a material resulting from prolonged application of constant structural stress at a constant temperature. For polymer, after instantaneous deformation, the creep can be divided into two main stages: the primary creep, steady state creep. In the primary creep, the creep strain rate decreases with time. In the steady state creep, the strain rate is constant. When load is removed after a creep time, strain recovery occurs, which means creep recovery. In general, in a creep test the total strain $\varepsilon$ is the sum of three separate parts $\varepsilon_{1}, \varepsilon_{2}$ and $\varepsilon_{3}$. The $\varepsilon_{1}$ and $\varepsilon_{2}$ is the immediate elastic 
deformation and delayed elastic deformation. $\varepsilon_{3}$ is the Newtonian flow [13]. Figure 11 shows the creep and recovery curves of polyurethane/clay C20A nanocomposites. With increasing clay content, the $\varepsilon_{1}$ and $\varepsilon_{2}$ decreased. Also, the addition of clay leads to a lower creep recovery. The creep compliance $\mathrm{J}$, i.e. the ratio of strain and applied stress can be expressed as: $\mathrm{J}=\mathrm{J}_{1}+\mathrm{J}_{2}+\mathrm{J}_{3}$. For a crosslinked or highly crystalline polymers, $\mathrm{J}_{3}$ can be zero approximately [13]. Figure 12 shows the creep compliance curves for polyurethane with different clay contents. The quantitatively description of creep can be made according to a generalized Voigt model based on the creep compliance data as shown in equation (3). And the retardation spectrum can be derived using Laplace transform. Like relaxation time spectrum, the retardant spectrum $L(\lambda)$ value is related to creep rate as shown in Equation (4). Figure 13 shows the retardant time spectra for polyurethane with different clay contents. The instantaneous compliance, equilibrium compliance, creep ratio, creep rate, and retardant time are listed in Table 3. Here, the retardant time $\lambda$ was taken from the position of the maximum of the second peak of the retardation spectra. We choose this peak because the retardant time obtained from this peak is in the same magnitude as the relaxation time we discussed above. With increasing clay content, the instantaneous compliance decrease, which is in consistent with the modulus result. Also, the equilibrium compliance nearly doesn't change except for $5 \% \mathrm{C} 20 \mathrm{~A}$, like the equilibrium stress during the stress relaxation experiment. The creep ratio and rate increase and the retardant time increased with the addition of clay. These results agree with the stress relaxation results.

\section{Conclusion}

Microphase separation of polyurethane nanocomposite was characterized. FTIR AFM and SAXS suggested that with the addition of clay, the size of hard domain decreased and a more complete phase separation occurred. Based on the stress relaxation modulus and creep compliance data, the relaxation and retardant time spectrum were derived according to a 
generalized Maxwell model and Voigt model with a Tikhonov regularization method, respectively. Based on stress relaxation of blank PU, the characteristic relaxation peaks in the spectrum were attributed. At a strain below $100 \%$, the disentanglement of the molecular chains in the soft domain should be mainly responsible for the stress relaxation process. It was found that relaxation time decrease with increasing hard segment content. The addition of clay increases the relaxation time. The shift in the relaxation time was related to microphase separation of polyurethane. At large strains, the occurred multi-peak relaxations were related to the breakup of interconnected hard domains, pull-out of soft segment chains from hard domains and the disentanglement of the molecular chains in the soft phase, the former two processes are irreversible. The relaxation spectrum $\mathrm{H}(\tau)$ can be used to characterize the rupture of interconnected hard domain of polyurethane and provide a method to examine the complicated relaxation processes for a multi-phase and multi-component polymer system. In addition, the creep results are in consistent with that of the stress relaxation.

\section{References}

1. Wang, Z., Pinnavia, T.J. Chem. Mater. 1998, 10, 3769.

2. Zilg, C., Thomann, R., Mulhaupt, R., Finter, J. Adv. Mater. 1999, 11, 49.

3. Yao, K.J., Song, M., Hourston, D.J., Luo, D.Z. Polymer 2002, 3, 1017.

4. Tien, Y.I., Wei, K.H. Polymer 2001, 42, 3213.

5. Tien, Y.I., Wei, K.H. Macromolecules 2001, 34, 9045.

6. Osman, M.A., Mittal, V., Morbidelli, M., Suter, U.W. Macromolecules 2003, 36, 9851.

7. Song, M., Hourston, D.J; Yao, K.J., Toly, J.K.H. J. Appl. Polym. Sci. 2003, 90, 3239.

8. Rhoney. I., Brown, S., Hudson, N.E., Pethrick, R.A., J. Appl. Polym. Sci. 2004, 91, 1335 .

9. Solarski, S., Benali, S., Rochery, M., Devaux, E., Alexandre, M., Monteverde, F., 
Dubois, P. J. Appl. Polym. Sci. 2005, 95, 238.

10. Song, M., Xia, H.S., Yao, K.J., Hourston, D.J. Eur. Polym. J. 2005, 41, 259.

11. Dai, X.H., Xu, J., Guo, X.L., Lu, Y.L., Shen, D.Y., Zhao, N., Luo, X.D., Zhang, X.L. Macromolecules 2004, 37, 5615.

12. Hepburn C. Polyurethane Elastomer, Applied Science Publishers, London 1982.

13. Ferry, J.D. Viscoelastic Properties of Polymers, Third Edition, John Wiley \& Sons, Inc, New York, 1980.

14. Mours, M., Winter, H.H., Mechanical Spectroscopy. Tanaka, T. Ed, Experimental Methods in Polymer Science: Modern Methods in Polymer Research and Technology, Academic Press. San Diego CA. 2000, p. 495-546.

15. Honerkamp, J., Weese, J. Rheol. Acta 1993, 32, 57.

16. Cotton, G. R., Boonstra, B.B. J. Appl. Polym. Sci. 1965, 9, 3395

17. Seymour, R.W., Ester G.M., Cooper, S.L. Macromolecules 1970, 3, 579.

18. Granddy, D.B., Hourston, D.J., Price, D.M., Reading M., Silva, G.G., Song M., Sykes P.A. Macromolecules 2000, 33, 9348.

19. Eaton, P.J., Estarlich, F.F., Ewen, R.J., Nevell, T.G., Smith, J.R., Tsibouklis, J., Langmuir 2002, 18,10011.

20. Eaton, P.J., Graham, P., Smith, J.R., Smart, J.D., Nevell, T.G., Tsibouklis, J. Langmuir $2000,16,7887$

21. Garrett, J.T., Siedlechi, C.A., Runt, J., Macromolecules 2001, 34, 7066.

22. Xia, H.S., Shaw, S.J., Song, M. Polymer Int. 2005, 54, 1392

23. Saiani, A., Rochas, C., Eeckhaut, G., Daunch, W. A., Leenslag, J.-W., Higgins, J. S., Macromolecules 2004, 37, 1411.

24. Li, W., Ryan, A. J., Meier, I. K. Macromolecules 2002, 35, 5034. 
25. Chasset, R., Thirion, P., “ Proceedings of the Conference on Physics of Non-Crystalline Solid”, Prins, J.A., Ed., North-Holland Publishing Co.: Amsterdan, 1965, p 345.

26. Williams, G., Watts, D.C. Trans. Faraday Soc. 1971, 67, 1323.

27. Curro, J.G., Pincus, P. Macromolecules 1983, 16, 559.

28. Hotta, A., Clarke, S.M., Terentjev, E.M. Macromolecules 2002, 35, 271.

29. Baeurle, S.A., Hotta, A., Gusev, A.A. Polymer 2005, 46, 4344.

30. Gurtovenko, A.A., Gotlib, Y.Y. J Chem. Phys. 2001, 115, 6785.

31. Ortiz, C., Ober, C.K., Kramer, E.J. Polymer 1998, 39, 3713.

32. Wang, C.B., Cooper, S.L. Macromolecules 1983, 16, 775.

33. Seymour, R.W., Allegrezza A.E., Cooper, S.L. Macromolecules 1973, 6, 896.

34. Ishihara, H., Kimura, I., Saito, K., Ono, H. J. Macromol, Sci. Phys. 1974, B10, 591.

35. Desper, C.R., Schneider, N.S., Jasinski, J.P., Lin, J.S. Macromolecules 1985, 18, 2755. 


\section{Figure Captions}

Figure 1 FTIR spectra of polyurethane/clay C20A nanocomposites

Figure 2 Variation of hydrogen index with the clay content

Figure 3 AFM tapping-mode phase image of polyurethane and polyurethane/3\% clay C20A nanocomposite

Figure 4 Stress relaxation curves of polyurethane with different hard segment contents at $100 \%$ strain

Figure 5 Relaxation time distribution curves of polyurethane with different hard segment contents

Figure 6 Variation of characteristic relaxation time with different hard segment contents

Figure 7 Effect of strain on the relaxation spectrum of blank polyurethane

Figure 8 Stress relaxation curves of polyurethane/clay C20A nanocomposites at $100 \%$ strain

Figure 9 Relaxation time distribution curves of polyurethane/clay C20A nanocomposites

Figure 10 Effect of strain on the relaxation spectrum of polyurethane/3\%clay nanocompsoite

Figure 11 Creep and recovery curves of polyurethane/clay C20A nanocomposites

Figure 12 Creep compliance vs time curves of polyurethane/clay C20A nanocomposites

Figure 13 Retardant time distribution curves of polyurethane/clay nanocomposites 
Table 1 Stress relaxation data of unfilled polyurethane at different hard segment contents

\begin{tabular}{cccccc}
\hline Sample & $\begin{array}{c}\text { Initial stress } \\
\sigma_{0}(\mathrm{MPa})\end{array}$ & $\begin{array}{c}\text { Equilibrium } \\
\text { stress } \sigma_{\mathrm{e}}(\mathrm{MPa})\end{array}$ & $\begin{array}{c}\text { Relaxation ratio } \\
\left(\sigma_{0}-\sigma_{\mathrm{e})} / \sigma_{0}\right.\end{array}$ & $\begin{array}{c}\text { Relaxation rate at } \\
60 \mathrm{~s}\end{array} \times 10^{-4}$ & $\begin{array}{c}\text { Relaxation } \\
\text { time } \tau(\mathrm{s})\end{array}$ \\
\hline PU-16 & 0.67 & 0.63 & 0.050 & 1.22 & 116.6 \\
PU-26 & 1.44 & 1.17 & 0.188 & 6.80 & 31.9 \\
PU-36 & 3.01 & 2.12 & 0.296 & 26.8 & 11.6 \\
PU-46 & 10.26 & 5.99 & 0.416 & 72.2 & 7.0 \\
\hline
\end{tabular}

* Relaxation rate was obtained from equation 2, and the characteristic relaxation time $\tau$ was taken from the position of the maximum in the short time-relaxation peak. For PU-46, the first wide peak was split into two peaks by using an origin fitting program and the $\tau$ value was taken from the first short time-relaxation peak.

Table 2 Stress relaxation data of polyurethane/clay nanocomposites at $26 \mathrm{wt} \%$ hard segment content.

\begin{tabular}{cccccc}
\hline Sample & $\begin{array}{c}\text { Initial stress } \sigma_{0} \\
(\mathrm{MPa})\end{array}$ & $\begin{array}{c}\text { Equilibrium } \\
\text { stress } \sigma_{\mathrm{e}}(\mathrm{MPa})\end{array}$ & $\begin{array}{c}\text { Relaxation ratio } \\
\left(\sigma_{0}-\sigma_{\mathrm{e}}\right) \sigma_{0}\end{array}$ & $\begin{array}{c}\text { Relaxation rate at } \\
60 \mathrm{~s}\end{array} \times 10^{-4}$ & $\begin{array}{c}\text { Relaxation } \\
\text { time } \tau(\mathrm{s})\end{array}$ \\
\hline PU-26 & 1.44 & 1.17 & 0.188 & 6.80 & 31.9 \\
$1 \% \mathrm{C} 20 \mathrm{~A}$ & 1.52 & 1.20 & 0.210 & 8.04 & 43.1 \\
$3 \% \mathrm{C} 20 \mathrm{~A}$ & 1.63 & 1.23 & 0.241 & 9.67 & 61.8 \\
$5 \% \mathrm{C} 20 \mathrm{~A}$ & 1.87 & 1.39 & 0.257 & 11.50 & 46.3 \\
\hline
\end{tabular}

* Relaxation rate was obtained from equation 2, and the relxation time $\tau$ was taken from the position of the maximum in the short time-relaxation peak.

Table 3 Creep data of polyurethane/clay nanocomposites at 26 wt\% hard segment content.

\begin{tabular}{cccccc}
\hline Sample & $\begin{array}{c}\text { Instantaneous } \\
\text { compliance } \mathrm{J}_{0} \\
\left(\mu \mathrm{m}^{2} / \mathrm{N}\right)\left(\times 10^{5}\right)\end{array}$ & $\begin{array}{c}\text { Equilibrium } \\
\text { compliance } \mathrm{J}_{\mathrm{e}} \\
\left(\mu \mathrm{m}^{2} / \mathrm{N}\right)\left(\times 10^{5}\right)\end{array}$ & $\begin{array}{c}\text { Creep ratio } \\
\left(\mathrm{J}_{\mathrm{e}}-\mathrm{J}_{0}\right) / \mathrm{J}_{0}\end{array}$ & $\begin{array}{c}\text { Creep rate at } 60 \\
\mathrm{~s}\end{array} \times 10^{-2}$ & $\begin{array}{c}\text { Retardant } \\
\text { time } \lambda(\mathrm{s})\end{array}$ \\
\hline $\mathrm{PU}-26$ & 3.438 & 4.350 & 0.265 & 6.74 & 11.5 \\
$1 \% \mathrm{C} 20 \mathrm{~A}$ & 3.325 & 4.384 & 0.318 & 6.90 & 21.4 \\
$3 \% \mathrm{C} 20 \mathrm{~A}$ & 2.920 & 4.329 & 0.483 & 7.17 & 24.0 \\
$5 \% \mathrm{C} 20 \mathrm{~A}$ & 2.840 & 4.031 & 0.419 & 7.02 & 23.8 \\
\hline
\end{tabular}

*The creep rate was obtained from equation 4 , and the retardant time $\lambda$ was taken from the position of the maximum of the second peak of the retardation spectra. 


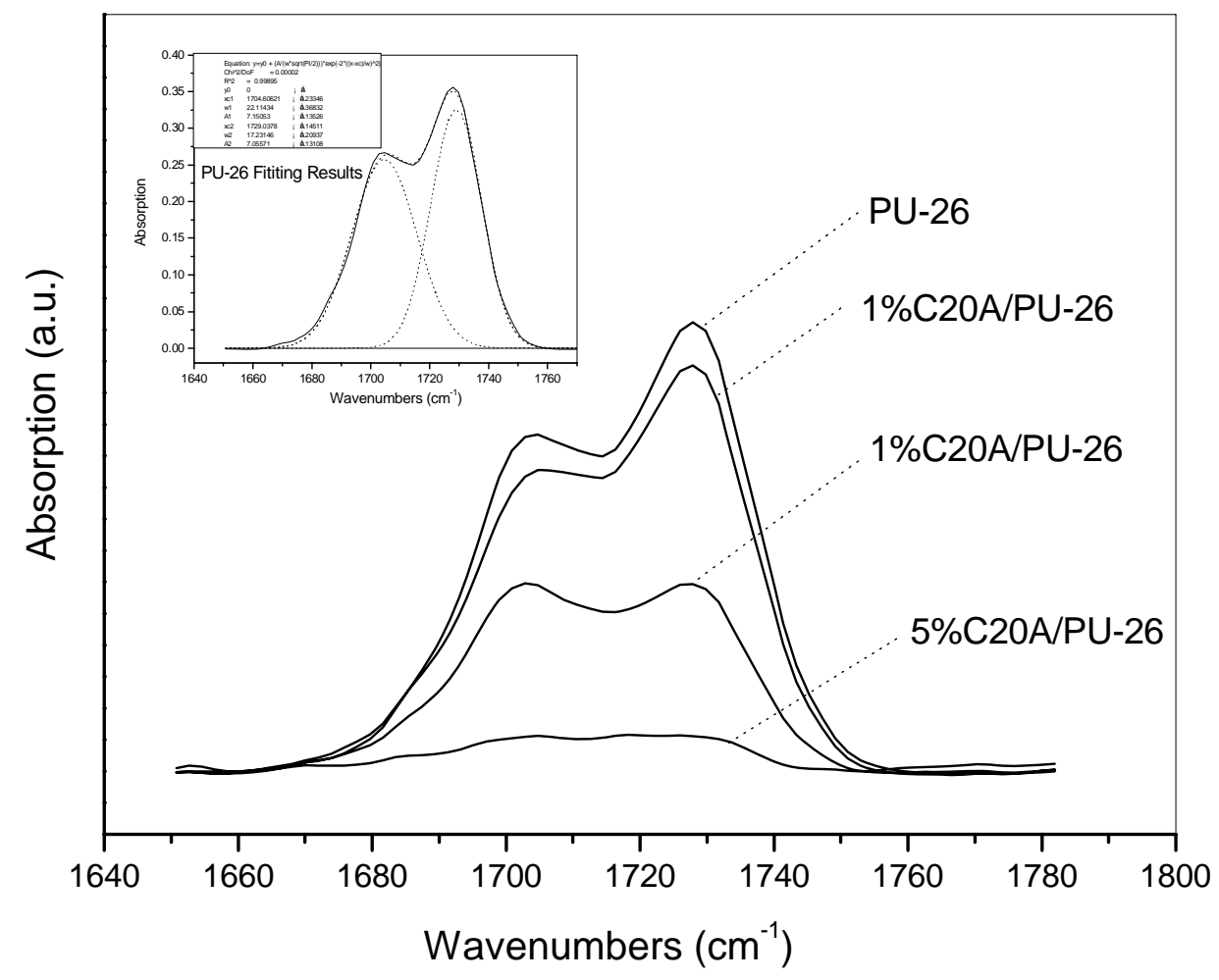

Figure 1 FTIR spectra of polyurethane/clay C20A nanocomposites 


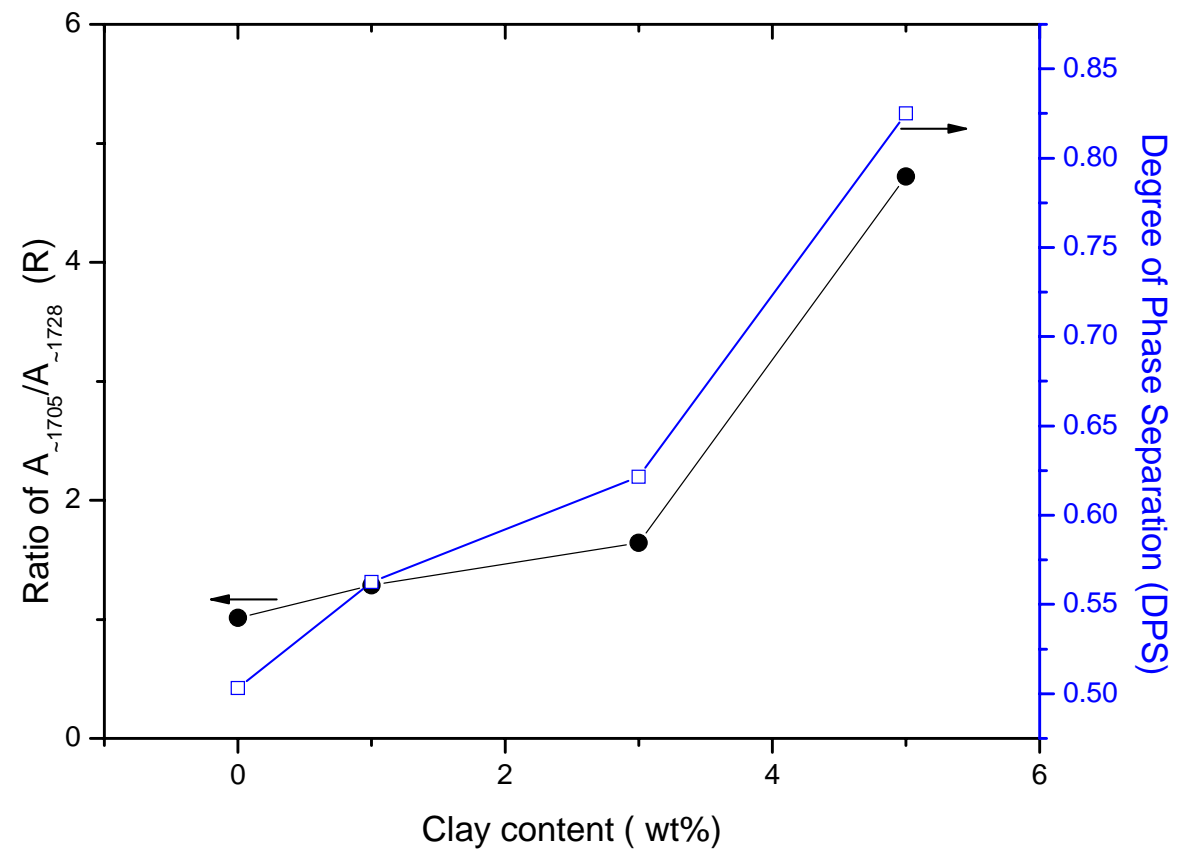

Figure 2 Variation of hydrogen index R and degree of phase separation (DPS) with the clay content 

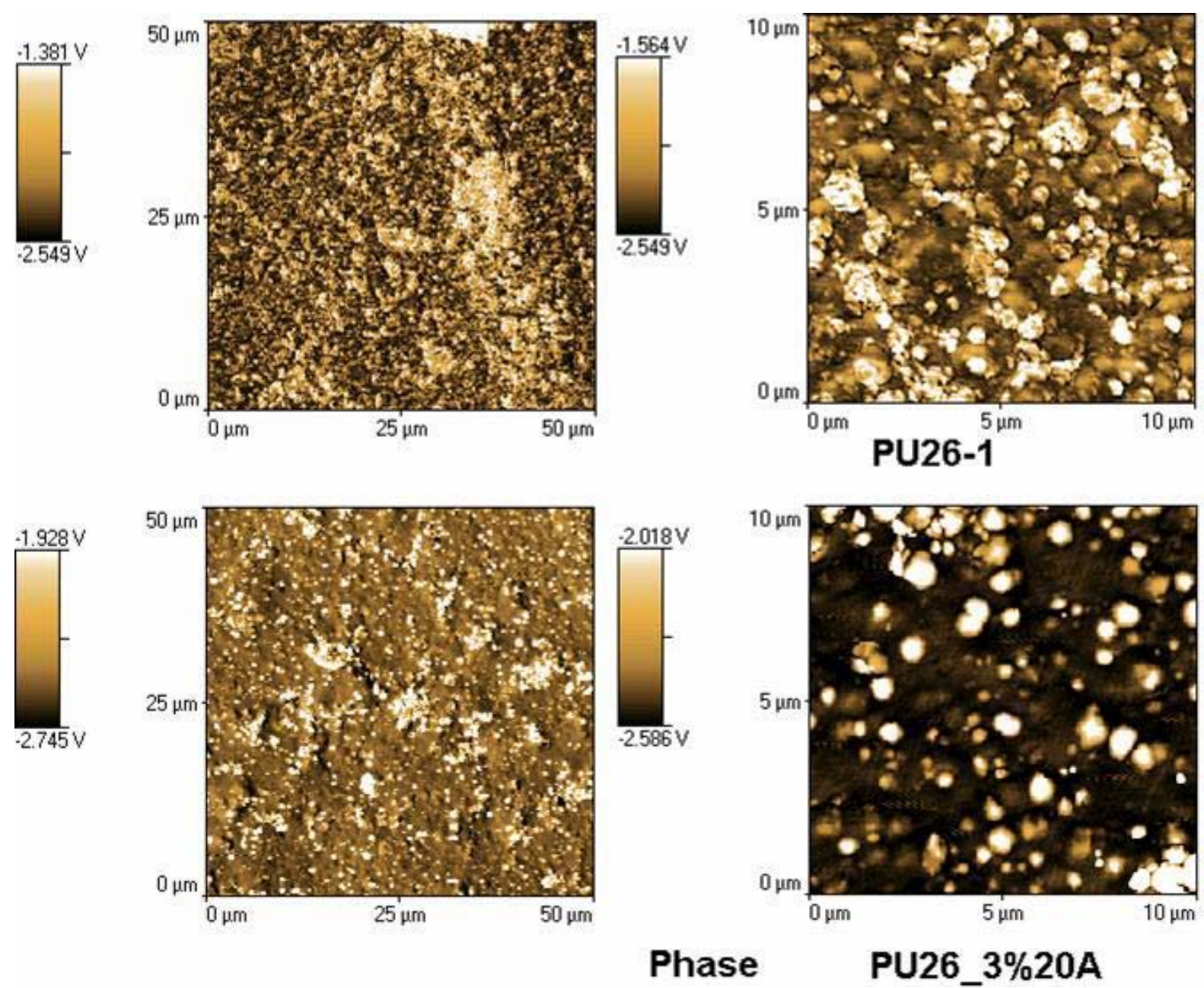

Figure 3 AFM tapping-mode phase image of polyurethane and polyurethane/3\% clay C20A nanocomposite 


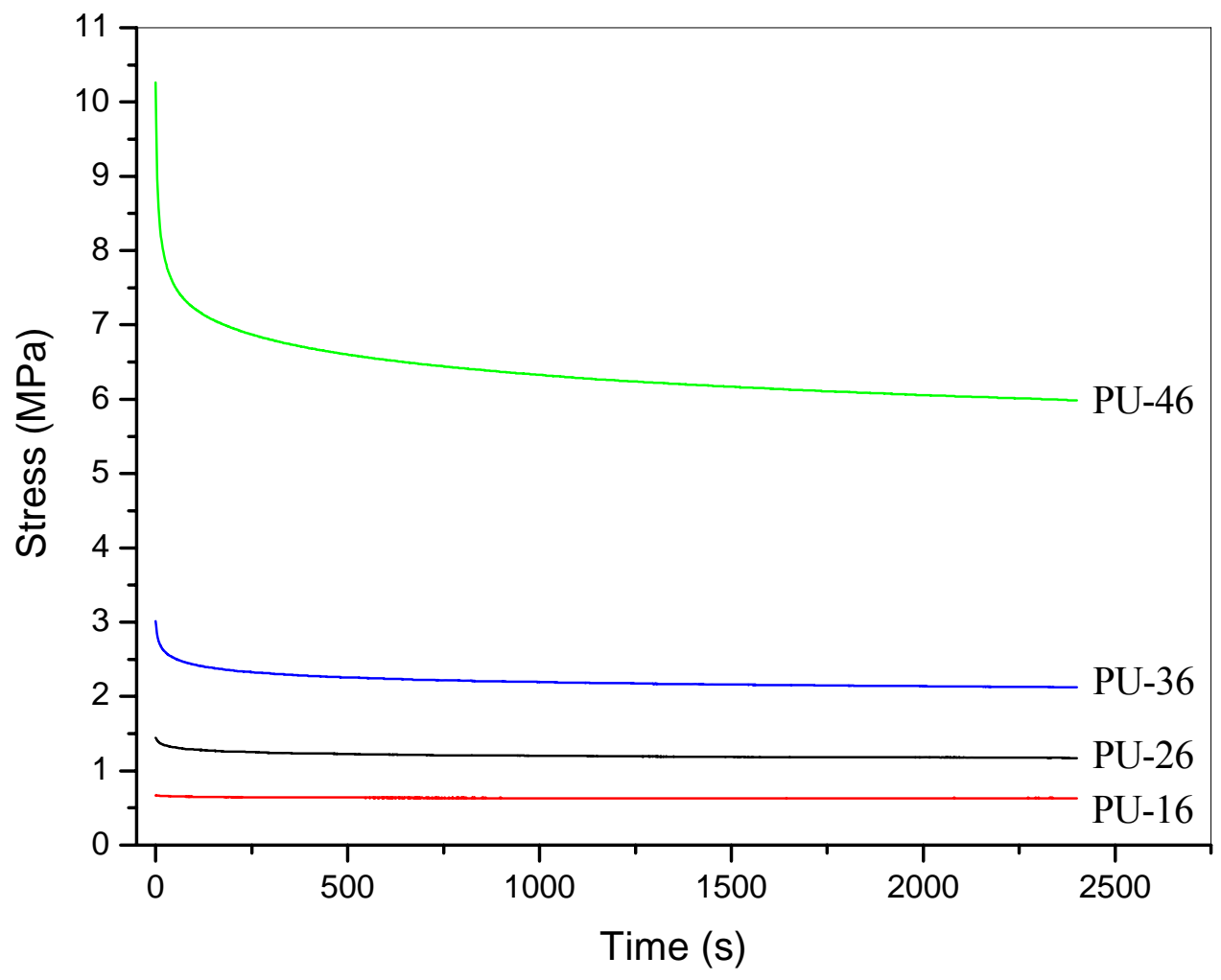

Figure 4 Stress relaxation curves of polyurethane with different hard segment contents at $100 \%$ strain 


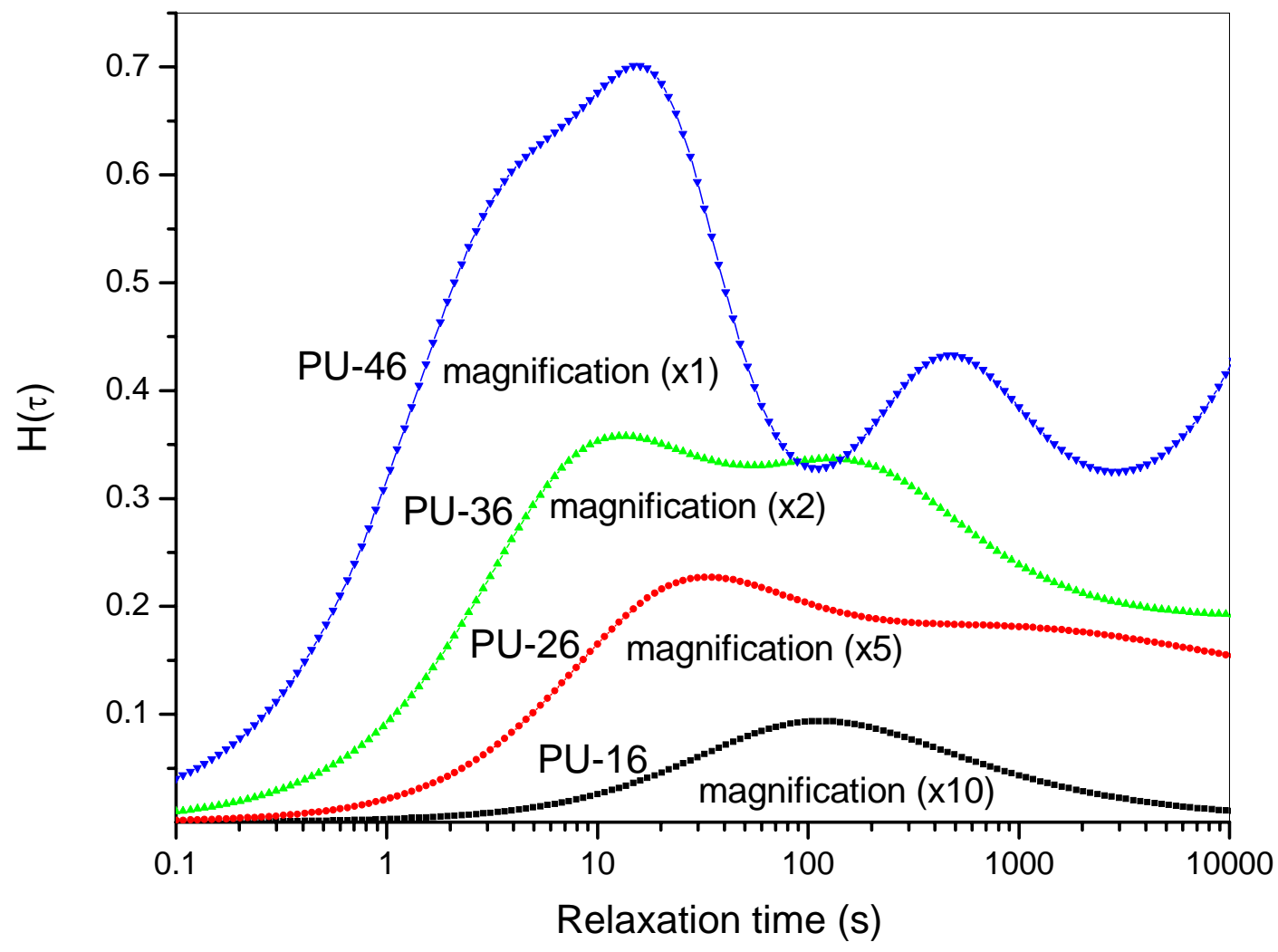

Figure 5 Relaxation time distribution curves of polyurethane with different hard segment contents 


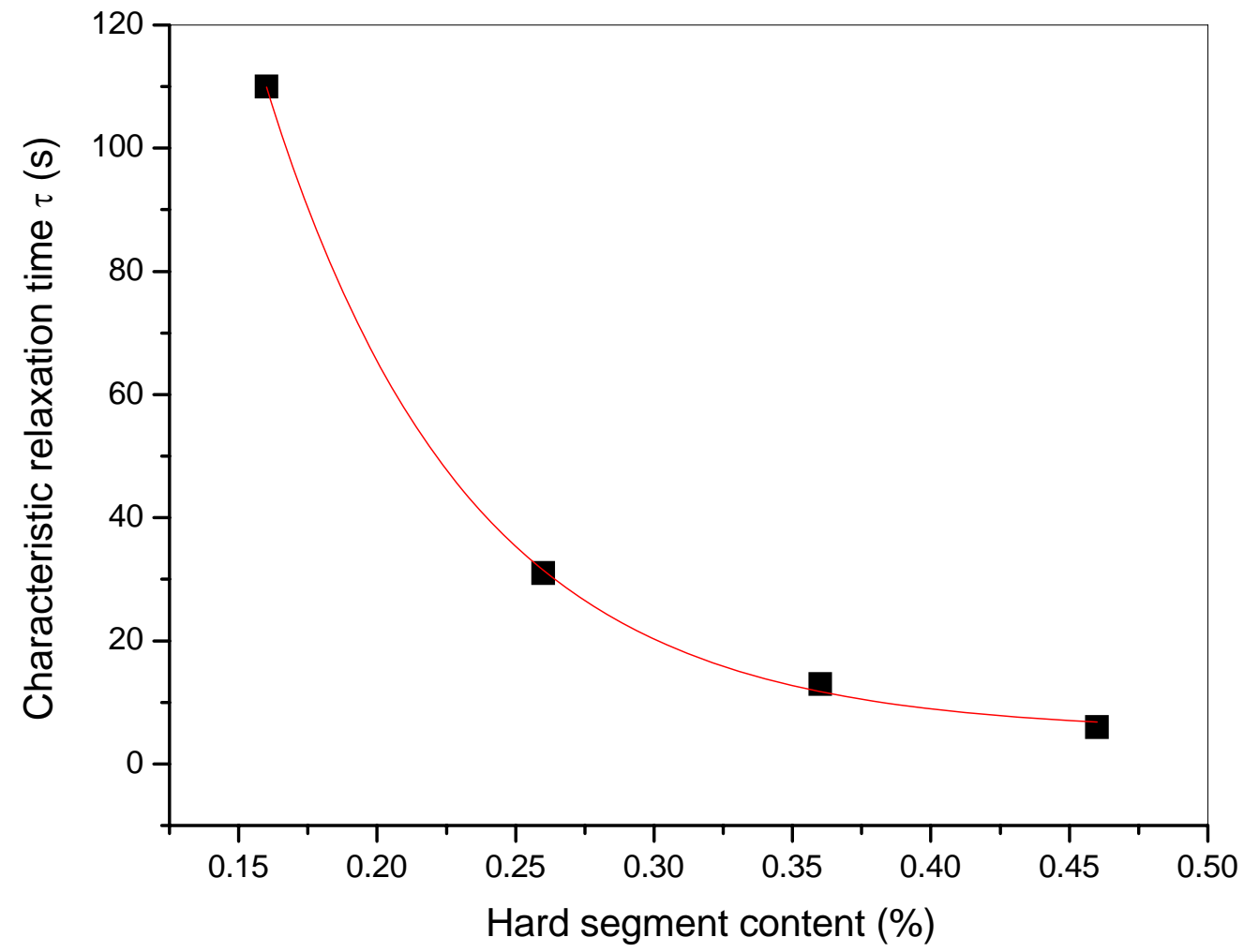

Figure 6 Variation of characteristic relaxation time with different hard segment contents 


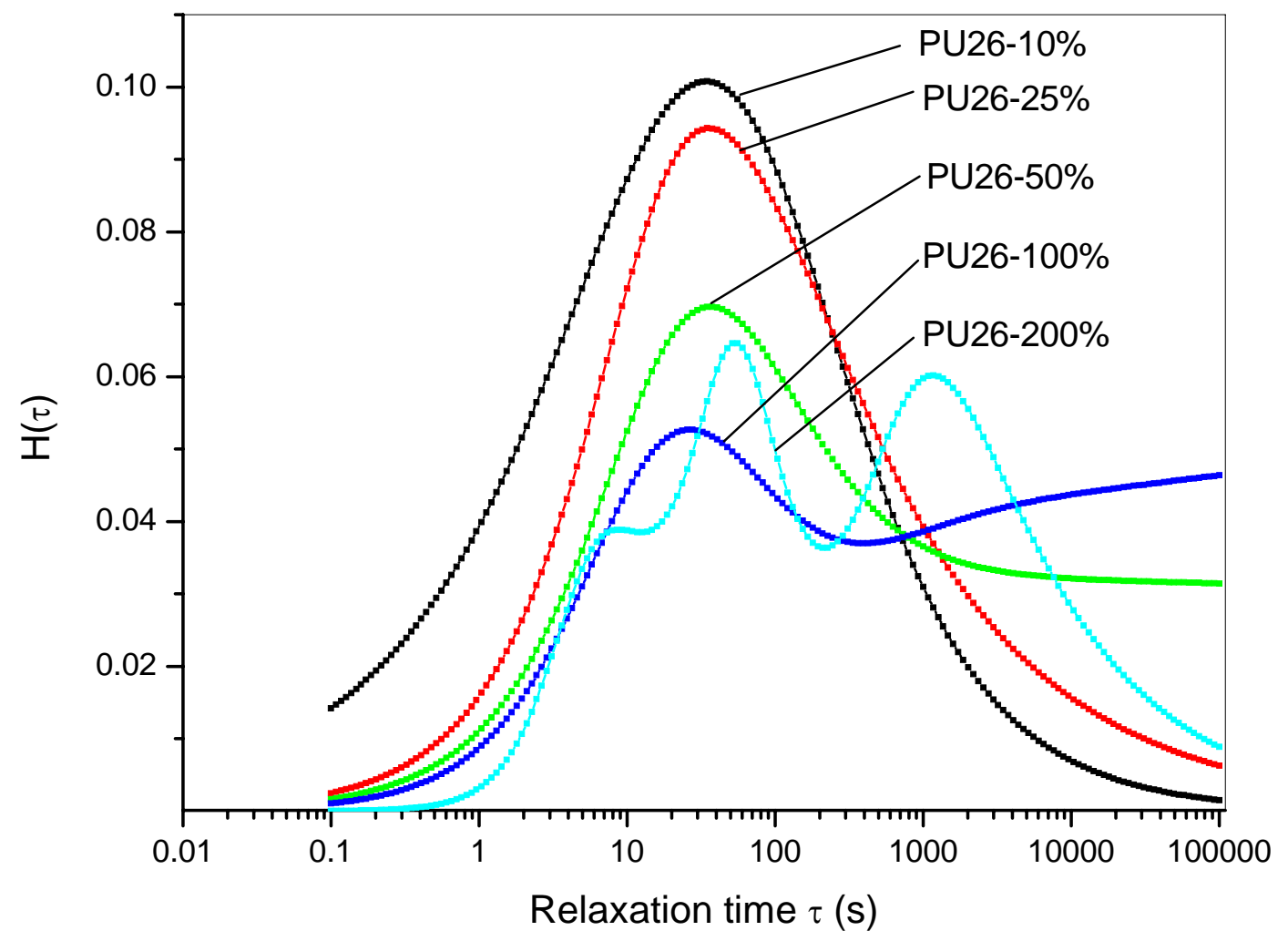

Figure 7 Effect of strain on the relaxation spectrum of blank polyurethane 


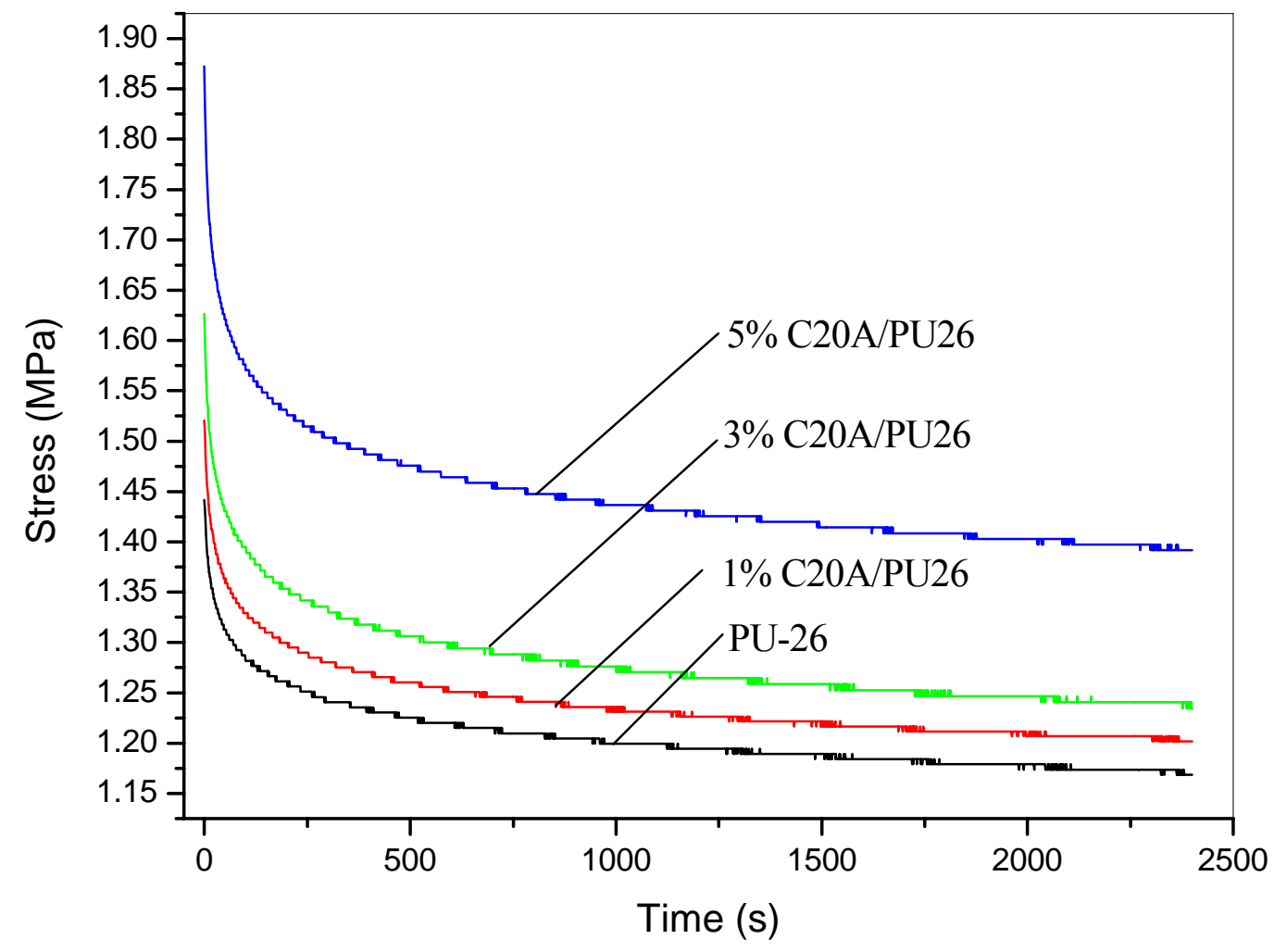

Figure 8 Stress relaxation curves of polyurethane/clay C20A nanocomposites at $100 \%$ strain 


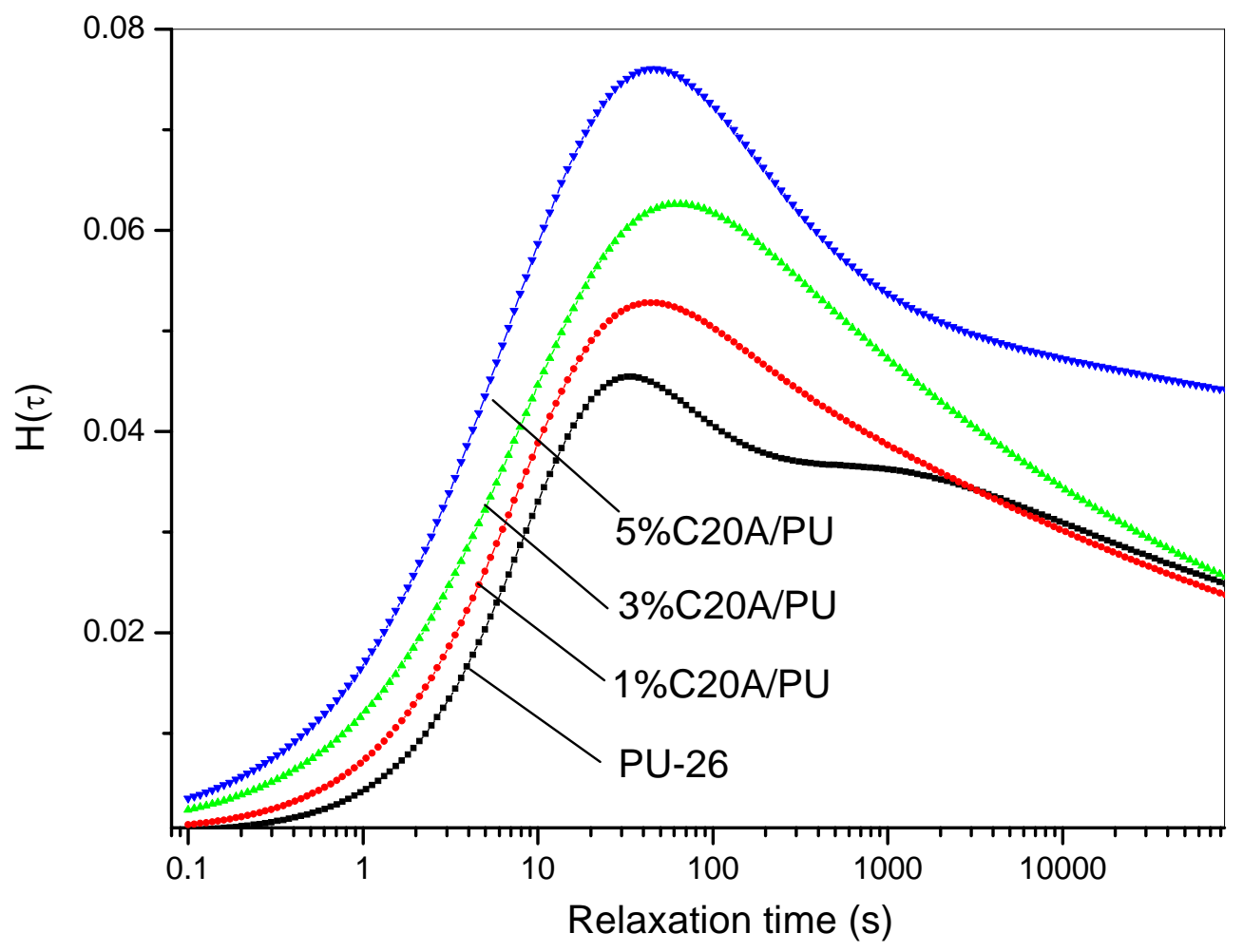

Figure 9 Relaxation time distribution curves of polyurethane/clay C20A nanocomposites 


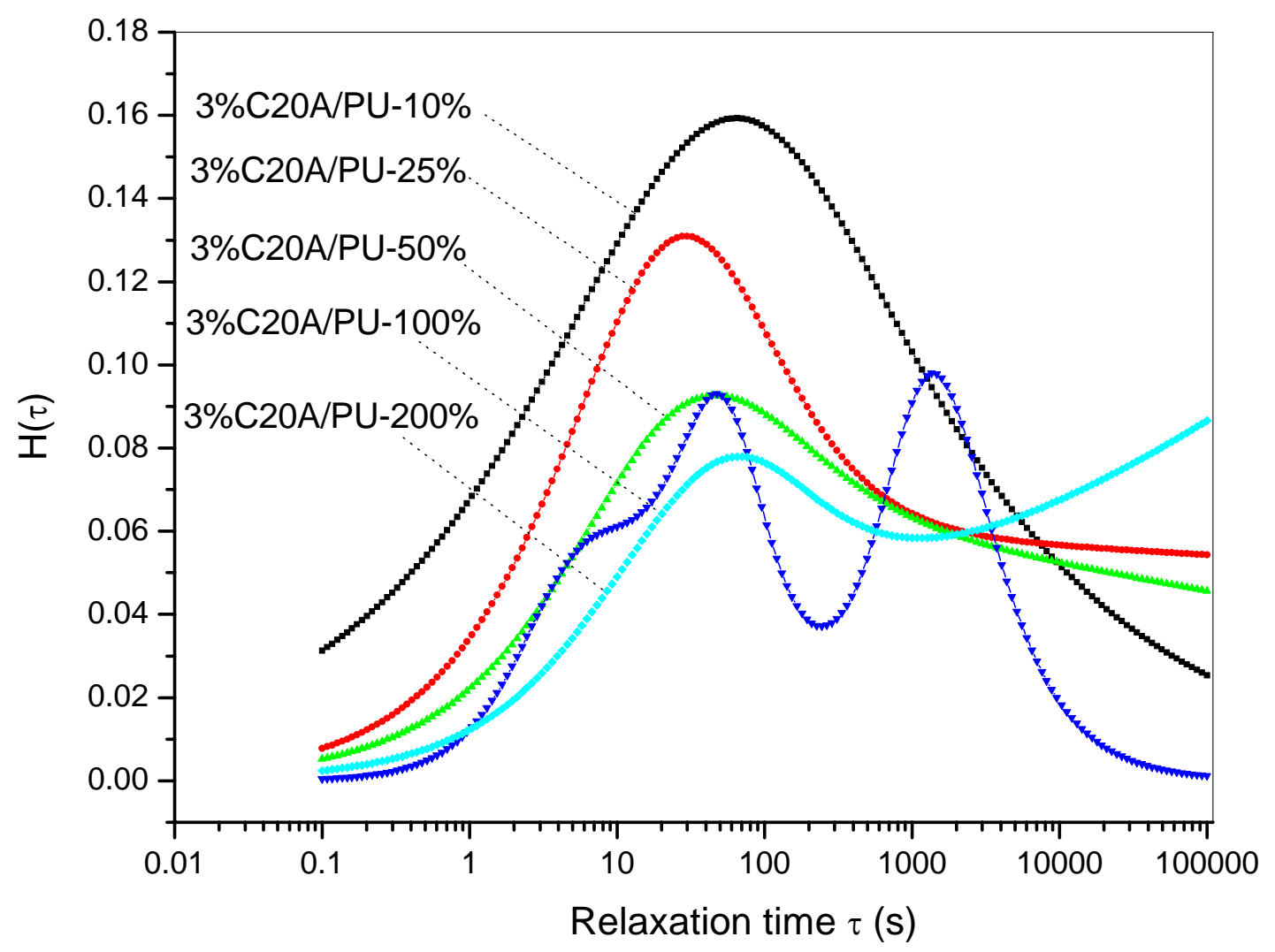

Figure 10 Effect of strain on the relaxation spectrum of polyurethane/3\%clay nanocompsoite 


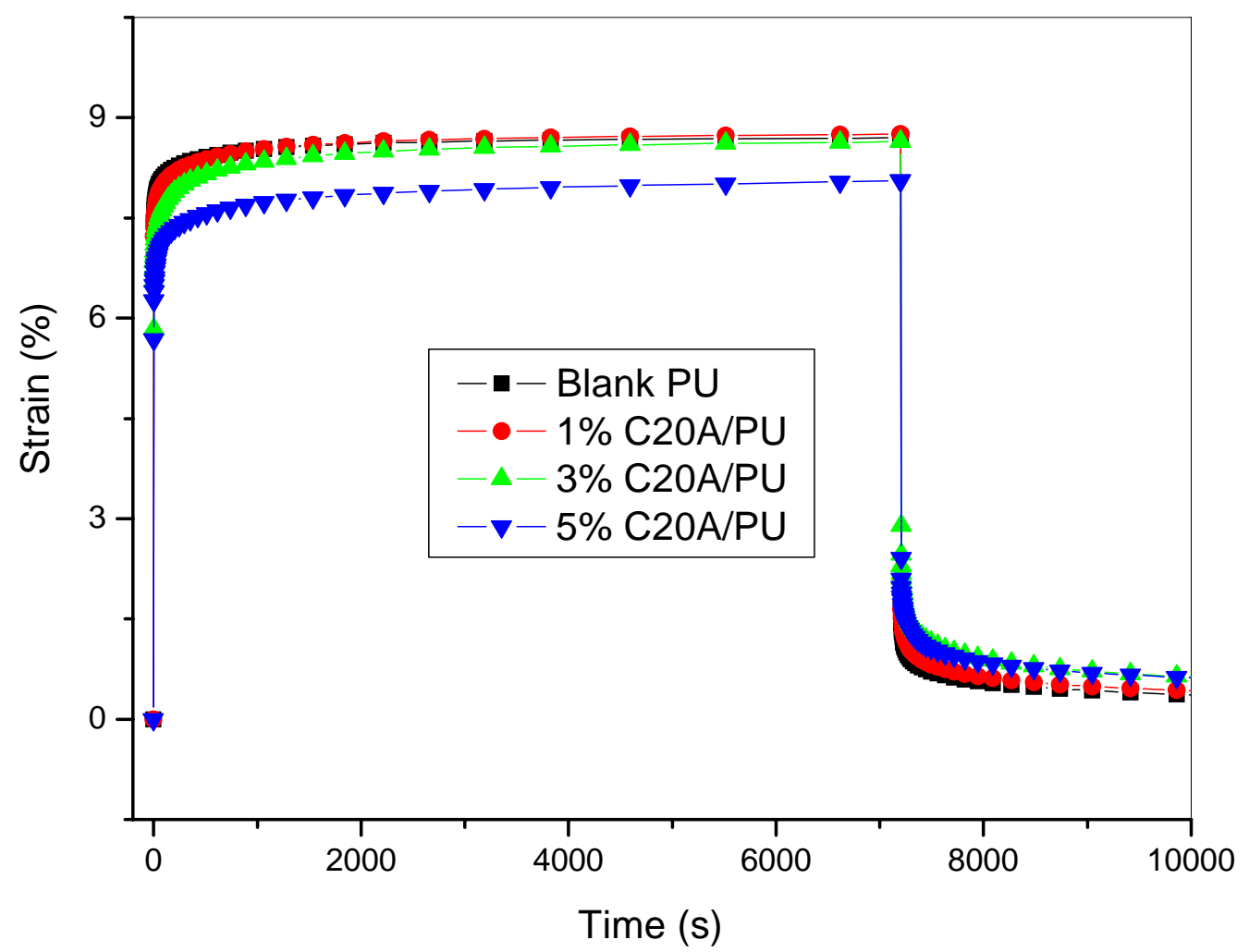

Figure 11 Creep and recovery curves of polyurethane/clay C20A nanocomposites 


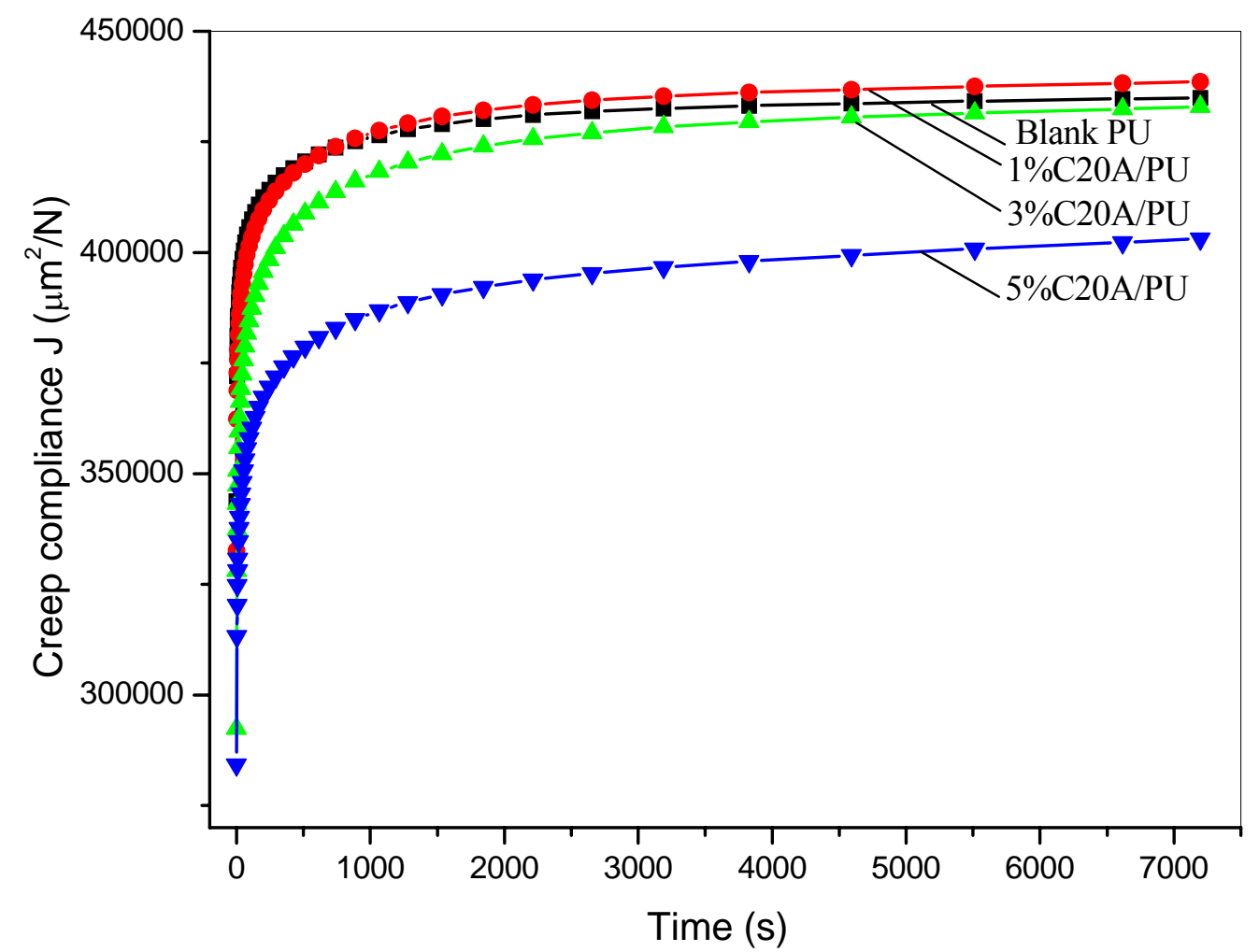

Figure 12 Creep compliance vs time curves of polyurethane/clay C20A nanocomposites 


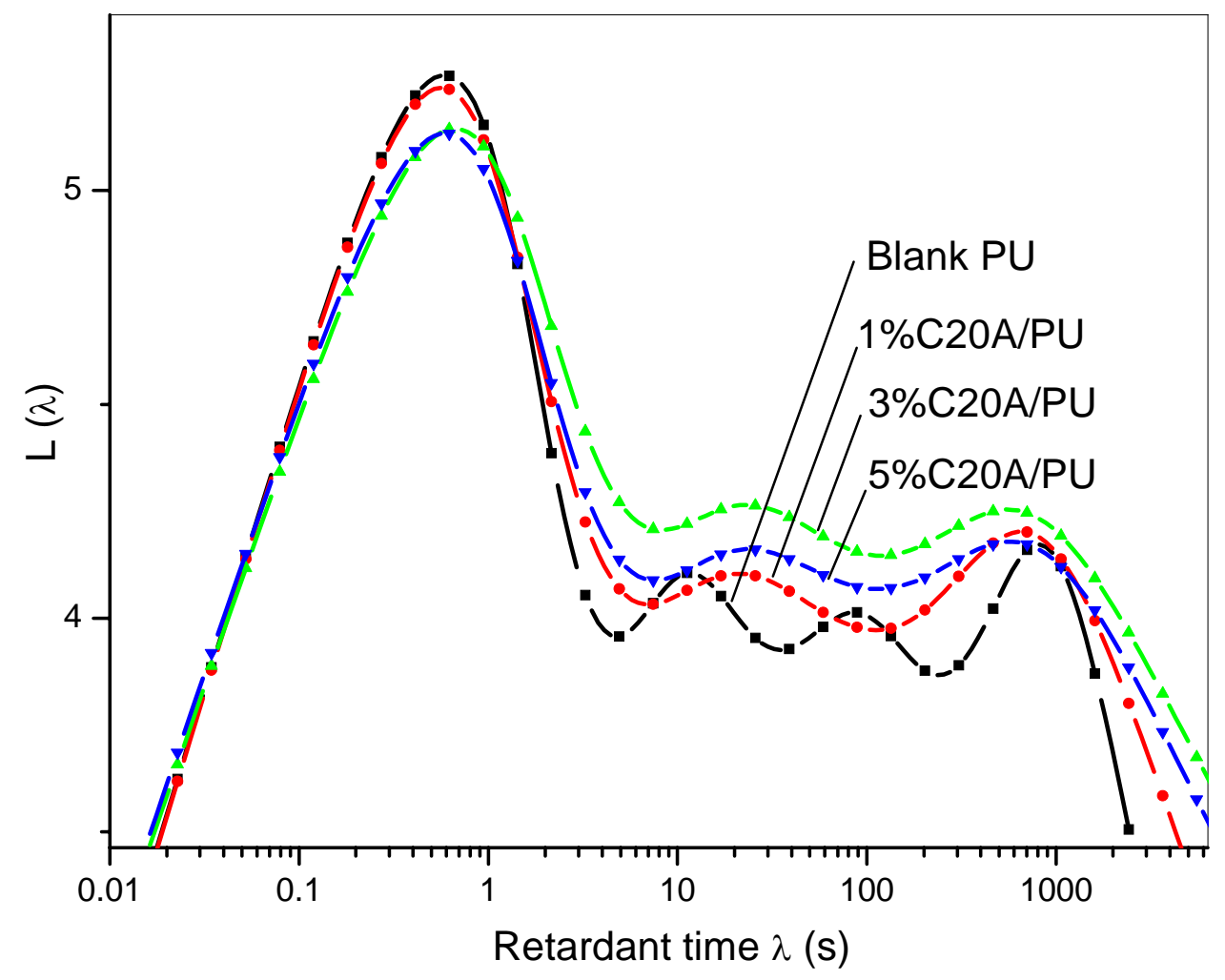

Figure 13 Retardant time distribution curves of polyurethane/clay nanocomposites 